1st ed. 2020, XXX, 770 p. 160 illus., 60 illus. in color.

\section{Printed book}

Softcover

Ca. 249,99 € | Ca. £219.99 | Ca.

$\$ 299.99$

${ }^{[1]}$ Ca. $267,49 €(D) \mid$ Ca. $274,99 €(A)$

| Ca. CHF 295,00

\section{eBook}

Available from your library or springer.com/shop

MyCopy [3]

Printed eBook for just

$€$ | \$ 24.99

springer.com/mycopy
V.S. Rathore, N. Dey, V. Piuri, R. Babo, Z. Polkowski, J.M.R.S. Tavares (Eds.)

\section{Rising Threats in Expert Applications and Solutions}

Proceedings of FICR-TEAS 2020

Series: Advances in Intelligent Systems and Computing

- Presents innovative work in the field of computational intelligence and security

- Discusses the outcomes of FICR-TEAS 2020, organized by IIS University Jaipur, Rajasthan, India

- Serves as a reference resource for researchers and practitioners in academia and industry

This book presents high-quality, peer-reviewed papers from the FICR International Conference on Rising Threats in Expert Applications and Solutions 2020, held at IIS University Jaipur, Rajasthan, India, on January 17-19, 2020. Featuring innovative ideas from researchers, academics, industry professionals and students, the book covers a variety of topics, including expert applications and artificial intelligence/machine learning; advanced web technologies, like IoT, big data, and cloud computing in expert applications; information and cybersecurity threats and solutions; multimedia applications in forensics, security and intelligence; advances in app development; management practices for expert applications; and social and ethical aspects of expert applications in applied sciences.
Order online at springer.com / or for the Americas call (toll free) 1-800-SPRINGER /

or email us at: customerservice@springernature.com. / For outside the Americas call +49 (0) 6221-345-4301 / or email us at: customerservice@springernature.com.

The first $€$ price and the $£$ and $\$$ price are net prices, subject to local VAT. Prices indicated with [1] include VAT for books; the $€(D)$ includes $7 \%$ for Germany, the $€(A)$ includes $10 \%$ for Austria. Prices indicated with [2] include VAT for electronic products; 19\% for Germany, 20\% for Austria. All prices exclusive of carriage charges. Prices and other details are subject to change without notice. All errors and omissions excepted. [3] No discount for MyCopy. 